\title{
SUSTAINABILITY OF THE PROBIOTIC LACTOBACILLUS CASEI IN FORTIFIED INDIAN MILK CAKES UNDER DIFFERENT PRESERVATION CONDITIONS-EFFECTS OF CO-IMMOBILIZATION OF L. CASEI AND COMMERCIAL PREBIOTIC INULIN (CHICORY BASED) AND MILLET INULIN
}

\author{
DEBOLINA BANERJEE ${ }^{1}$, PUJA BAG ${ }^{1}$, RANJANA CHOWDHURY1* ${ }^{*}$ PINAKI BHATTACHARYA ${ }^{2}$ \\ ${ }^{1}$ Chemical Engineering Department, Jadavpur University, Kolkata 700032, India, ${ }^{2}$ Chemical Engineering Department, Heritage Institute of \\ Technology, Kolkata 700107, India \\ Email: ranjana.juchem@gmail.com
}

Received: 21 Sep 2016 Revised and Accepted: 17 Nov 2016

\begin{abstract}
Objective: The objective of the present article is to identify the most suitable Indian millet inulin for the growth of probiotic Lactobacillus casei and to evaluate the effects of the fortification vectors (probiotics and probiotic-prebiotic combination in immobilized conditions) and immobilization methods on the sustainability of L. casei in a fortified Indian sweet (milk cake) preserved under different conditions.

Methods: Inulin was extracted from pearl, finger and great millets. The concentrations of $L$. casei, grown on three millet inulins, were compared in $24 \mathrm{~h}$ batch culture. The $L$. casei and probiotic-prebiotic combinations namely $L$. casei-commercial inulin and $L$. casei-pearl millet inulin were immobilized using entrapment, external and internal microencapsulation methods. The Indian milk cake samples were fortified with the immobilized probiotic cells, co-immobilized probiotic-prebiotic combinations. The fortified samples were preserved at different conditions (temperature: $4{ }^{\circ} \mathrm{C}$ and- $20^{\circ} \mathrm{C}$; Time: $1-4 \mathrm{w}$ ). The sustainability of $L$. casei in the preserved samples was determined using spread plate method and the cell concentrations were compared among all fortified samples.
\end{abstract}

Results: Pearl millet inulin is determined to be the most suitable millet inulin for the growth of $L$. casei. The synergistic combination of $L$. casei-pearl millet inulin, co-immobilized with internal gelation technique is the best fortification vector for the viability of $L$. casei in preserved food samples.

Conclusion: The L. casei, co-immobilized with pearl millet inulin through internal gelation technique, can be utilized as an effective fortification vector for the sustainability of probiotic cells in preserved Indian milk cakes and similar food samples.

Keywords: Probiotic, Lactobacillus casei (L. casei), Prebiotic, Inulin, Pearl millet, Immobilization, Viability, Indian Milk cakes

(C) 2017 The Authors. Published by Innovare Academic Sciences Pvt Ltd. This is an open access article under the CC BY license (http://creativecommons.org/licenses/by/4. 0/) DOI: http://dx.doi.org/10.22159/ijpps.2017v9i1.15305

\section{INTRODUCTION}

In recent past, concepts of functional foods have moved progressively towards the development of dietary supplementation which plays an important role in maintaining a healthy gut microbial composition and activities. The consumption of probiotic products is constantly gaining popularity among the population throughout the globe. Nowadays, great attention has been given in extending the category of foods carrying probiotics in order to broaden the groups of people that usually have no access to probiotic food [1]. Probiotic products for human diet include nutraceuticals or functional foods, food ingredients and supplements that have an important effect on the intestinal microflora [2, 3]. A wide range of foods including fermented and non-fermented dairy products have been evaluated as possible probiotics carrier. Milk derivatives are considered an ideal vehicle for carrying living probiotic cells because of its high fat content and buffering properties that help the bacteria to overcome the stress factors in the gastrointestinal conditions. With the view of improving the survival of probiotics [4], the effectiveness of prebiotics are well approved. The prebiotics are complex carbohydrates which are available in non-digestible food ingredients and support the growth of probiotics [5]. The most common prebiotics, namely inulin is naturally found in many foods such as wheat, pearl millet (bajra), onions, garlic, leeks, asparagus and chicory roots [6].

Although inulin extracted from chicory roots is available commercially, extraction of inulin from other natural sources should also be conducted. Only a few studies have been conducted on the extraction of inulin from oat, wheat, daliah and garlic [7, 15]. The effect of inulin extracted from other sources on the growth and viability of probiotic cells should also be emphasised. The Indian millets, namely great millet (Sorghum bicolor; Indian name: jowar), pearl millet (Pennisetum glaucum; Indian name: bajra) and finger millet (Eleusine coracana; Indian name: ragi) are reported to be rich in inulin. However, no work is available in the literature on extraction and characterization of millet-based inulin.

The intended health benefits of probiotics can only be obtained when the food contains the required minimum viable microorganism count at the time of consumption. US FDA has recommended that minimum probiotic count in the probiotic food should be at the least $10^{6} \mathrm{CFU} \mathrm{ml}-1$ [8-10]. It is, therefore, important to ensure that probiotics must survive and retain their functional features during the entire food processing operations as well as over the product shelf life in order to maintain consumer confidence in probiotic products. In this regard, a number of efforts have been made to improve the robustness and the viability of the probiotics in the variety of functional foods. Many factors were found to influence the viability of probiotic cells in food products during processing and storage. In this context, microencapsulation is found to be the most potential approach for enhancing the survival of the probiotic microorganisms in the food products from processing to storage until consumption [11-14]. The present article is focused on the systematic studies on the following topics: a) extraction of inulin from Indian millets namely great millet (jowar), pearl millet (bajra) and finger millet (ragi) along with the assessment of their effectiveness as the substrate for the probiotic cells, namely, L. casei; selection of the most effective millet inulin thereof, b) assessment of the effects of co-immobilization of $L$. casei and inulin with respect to the enhancement of viability of the former in a traditional Indian food product called milk cake (an Indian cottage cheese or chhena based dairy product); comparison of the effectiveness of coimmobilized combination of probiotic L. casei and commercial inulin with that of $L$. casei and millet inulin, c) comparison of the performance of co-immobilized combination of L. casei and inulin prepared using different immobilization techniques. Although it is 
understandable that the sustainability of probiotic cells is expected to increase by co-immobilization of prebiotics along with probiotics, no such research studies is available in the literature. To the best of our knowledge, this is the first study addressing the above topics and the research findings will open up the possibility of utilisation of prebiotic inulin derived from abundant sources of Indian millet and development of food products fortified with co-immobilized probiotics and millet based prebiotics.

\section{MATERIALS AND METHODS}

\section{Microorganisms}

Lactobacillus casei (2651 1951 RPK) culture purchased from NCIM, Pune were used.

\section{Materials}

Food grade inulin, peptone, yeast extract, sodium acetate, dipotassium hydrogen phosphate, tri-ammonium citrate, magnesium sulphate, manganese sulphate, sodium chloride, disodium hydrogen phosphate, potassium dihydrogen phosphate and sodium chloride purchased from Himedia, India, were used. Sodium alginate, acetic acid, tween80, potassium dihydrogen phosphate, disodium hydrogen phosphate, calcium chloride, glycerol, sodium dodecyl sulphate (SDS), beef extract, calcium carbonate, lactose and ethanol purchased from Merck, India, were used.

Milk (Amul India pvt. Ltd.), seeds of pearl millet, great millet and finger millet (Andheri, Mumbai) and rice-bran oil purchased from the local market were used.

\section{Growth medium and other reagents}

\section{MRS medium}

\section{Composition}

Beef extract: $10 \mathrm{~g} / \mathrm{l}$; yeast extract: $5 \mathrm{~g} / \mathrm{l}$; peptone: $10 \mathrm{~g} / \mathrm{l}$; sodium acetate: $5 \mathrm{~g} / \mathrm{l}$; di-potassium hydrogen phosphate: $2 \mathrm{~g} / \mathrm{l}$; triammonium citrate: $2 \mathrm{~g} / \mathrm{l}$; magnesium sulphate: $0.05 \mathrm{~g} / \mathrm{l}$; manganese sulphate: $0.05 \mathrm{~g} / \mathrm{l}$ and lactose: $20 \mathrm{~g} / \mathrm{l} ; \mathrm{pH} 7$.

\section{Phosphate buffer (0.1M)}

\section{Composition}

Potassium di-hydrogen phosphate: $1.361 \mathrm{~g} / \mathrm{l}$; di-sodium hydrogen phosphate: $35 \mathrm{~g} / \mathrm{l}$ (to adjust the $\mathrm{pH}$ at 7 ).

\section{Peptone water}

\section{Composition}

Peptone digest: $10 \mathrm{~g} / \mathrm{l}$; sodium chloride: $5 \mathrm{~g} / \mathrm{l}$.

\section{Equipments}

Magnetic stirrer (Remi, India), constant temperature bath (S. C Dey and co., India), digital weighing machine (Sartorius), autoclave (Gurpreet engineering works), hot air oven (G. B. Enterprises, Kolkata, India), B. O. D incubator (G. B. Enterprises, Kolkata, India), laminar airflow (G. B. Enterprises, Kolkata, India), mixer-grinder (Crompton Greaves, Kolkata, India) and high speed homogenizer (Plasto Crafts (Model: Superspin $\mathrm{R}-\mathrm{V} / \mathrm{F}_{\mathrm{M}}$ ), India), refrigerator (Whirlpool; Corona Deluxe, India), freezer-20 ${ }^{\circ} \mathrm{C}$ (Blue Star, India)were used.

\section{Analytical instrument}

Optical microscope (Optika, Italy) was used.

\section{Extraction of inulin from Indian millets}

The prebiotic native sources, namely, pearl (bajra), finger (ragi) and great (jowar) millets were washed properly with distilled water. The same protocol followed for extraction of inulin from wheat, oat, daliah etc. has been used [15].

\section{Sterilization procedure}

MMRS medium, $2 \%$ sodium alginate solution and home-made sweet were autoclaved at $121^{\circ} \mathrm{C}$ for $15 \mathrm{~min}$.

\section{Pre-adaptation of Lactobacillus casei to different carbohydrate sources}

The probiotic bacteria, namely, Lactobacillus casei was pre-adapted to different carbohydrate sources, namely, lactose, commercial inulin and three millet inulins. For lactose, sterile modified de-Man Rogosa Sharpe (MMRS) medium was prepared by using $20 \mathrm{~g} / \mathrm{l}$ lactose as the carbohydrate source. Four other stock cultures were also prepared using MMRS media in which the food grade commercial inulin and three millet inulins at a concentration of $0.3225 \mathrm{~g} / \mathrm{l}$ were separately used as the carbohydrate source. Each medium was inoculated with $1 \%(\mathrm{v} / \mathrm{v})$ of $L$. casei and was incubated for $24 \mathrm{~h}$ at $37{ }^{\circ} \mathrm{C}$. The concentration of $0.3225 \mathrm{~g} / \mathrm{l}$ was chosen for each inulin sample because the maximum growth of $L$. casei on commercial inulin had been observed by the present researchers at this level [15]. Since the purity of each inulin extract is dependent on the natural source, different quantity of inulin extracts was required to prepare the inulin solution of equal strength.

\section{Determination of the effectiveness of millet inulins for the} growth of $L$. casei

Batch studies were conducted in three $250 \mathrm{ml}$ conical flasks using $100 \mathrm{ml}$ modified MRS medium containing lactose and different millet inulins. The concentration of millet inulin and lactose in the MMRS medium in each conical flask were $0.3225 \mathrm{~g} / \mathrm{l}$ and $20 \mathrm{~g} / \mathrm{l}$ respectively. The pearl millet inulin, finger millet inulin and great millet inulin were respectively used in the first, second and third flasks. Each flask was seeded with $10 \%(\mathrm{v} / \mathrm{v})$ stock culture of $L$. casei. The flasks were kept in an incubator for $24 \mathrm{~h}$ at $37^{\circ} \mathrm{C}$. The cell concentration in each flask was measured using spectrophotometric method determining the optical density of the growth medium at $600 \mathrm{~nm}$. The cell concentrations of growth medium in three flasks at $24 \mathrm{~h}$ were compared to identify the most effective millet inulin for the growth of L. casei.

\section{Characteristics of millet extracts}

FTIR analysis of the extracts of three millet sample has been carried out to determine the presence of inulin qualitatively. The quantity of inulin in each extract has been determined spectrophotometrically following the protocols described by Samanta Koruri et al. [16].

Co-entrapment and entrapment of Lactobacillus casei with and without inulin

The protocols described by Chan et al., 2011 and Yoo et al., 1996 have been principally followed $[17,18]$ for the entrapment and coentrapment. L. casei cultures, pre-adapted to lactose and commercial inulin were respectively spiked up to $20 \mathrm{~g} / \mathrm{l}$ lactose and $0.3225 \mathrm{~g} / \mathrm{l}$ commercial inulin and were individually mixed with $2 \%$ sterile sodium alginate solution in the volumetric ratio of 1:4. Each mixture was then added dropwise into a $1 \% \mathrm{CaCl}_{2}$ solution at room temperature and stirred continuously. The beads containing entrapped L. casei and co-entrapped L. casei and inulin were allowed to harden and were washed with saline water and stored at $4{ }^{\circ} \mathrm{C}$.

\section{Co-encapsulation and encapsulation of $L$. casei with and without} inulin through external gelation

For the co-encapsulation and encapsulation of $L$. casei with and without inulin, via external gelation method, the protocol suggested by Song et al., 2013 have been principally followed [19]. L. casei cultures, pre-adapted to lactose and commercial inulin were spiked with the respective carbohydrates up to the concentration levels as used for pre-adaptation, i.e., $20 \mathrm{~g} / \mathrm{l}$ and $0.3225 \mathrm{~g} / \mathrm{l}$ for lactose and inulin respectively. Each culture was mixed with sodium alginate solution in the volumetric ratio of $1: 4.1 \mathrm{ml}$ of the mixture was stirred with $5 \mathrm{ml}$ of vegetable oil. Tween 80 (emulsifier) and SDS were added to the resulting solution to maintain their concentrations at $0.2 \%$ and $0.25 \%$ respectively. This mixture was then stirred at $200 \mathrm{rpm}$ for $30 \mathrm{~min}$. $\mathrm{CaCl}_{2}$ was added quickly but gently down the side of a beaker, in which the mixture was taken. The formed microbeads were kept undisturbed for $30 \mathrm{~min}$. They were then filtered with muslin cloth. Finally, the microspheres were washed with $0.9 \%$ saline water containing $0.05 \%$ glycerol. The washed microbeads were stored at $4{ }^{\circ} \mathrm{C}$. 
Co-encapsulation and encapsulation of $L$. casei with and without inulin through internal gelation

The protocol suggested by Song et al., 2013 and Sultana et al., 2000 was principally followed with some modifications for the encapsulation of cells through internal gelation method $[19,20]$. L. casei cultures preadapted to lactose, commercial inulin and the millet inulin, most effective for the growth of the probiotic microorganism, were at first spiked with the respective carbohydrate sources as described in the case of entrapment and external gelation i. e up to $20 \mathrm{~g} / \mathrm{l}$ and $0.3225 \mathrm{~g} / \mathrm{l}$ for lactose and inulin samples respectively. Each culture was then individually mixed with $2 \%$ sodium alginate solution in the volumetric ratio of $1: 4 . \mathrm{CaCO}_{3}$ powder and Tween-80 were added to each mixture up to a concentration level of $0.8 \mathrm{~g} / \mathrm{l}$ and $0.5 \%(\mathrm{v} / \mathrm{v})$. This mixture was then combined with vegetable oil in the volumetric ratio of $1: 5$ and stirred at $300 \mathrm{rpm}$ for $30 \mathrm{~min}$. The temperature of the mixture was maintained at $25{ }^{\circ} \mathrm{C}$ by circulating water from a constant temperature bath and acetic acid was next added dropwise to the solution to release the $\mathrm{Ca}^{2+}$ from the insoluble $\mathrm{CaCO}_{3}$ powder. Microcapsules were formed and were filtered with a muslin cloth and washed with $1 \%(\mathrm{v} / \mathrm{v})$ aqueous tween 80 solution and distilled water. The microcapsules were then stored at $4{ }^{\circ} \mathrm{C}$.

\section{Microscopic characterization of beads and microcapsules}

The size analysis of the beads and microcapsules were done microscopically.

\section{Preparation of Indian cottage cheese for milk cakes}

Indian cottage cheese (chhena) was prepared from 1L milk. Firstly the milk was allowed to boil, followed by addition of lemon juice into it stirring continuously. When the milk curdled well, cottage cheese was strained using a muslin cloth and washed with water. After removing the excess water, $200 \mathrm{~g}$ chhena was obtained. The chhena was added to a pan and was mixed well with sugar and cardamom powder on a low flame until a mixture of thick consistency was obtained. The mixture was then cooled and kneaded properly and was autoclaved at $120^{\circ} \mathrm{C}$.

\section{Preparation of milk cakes with and without fortification with} probiotic or probiotic--prebiotic microcapsules

The sterile $200 \mathrm{~g}$ chhena, as described above, was divided into eight parts-first part was mixed with probiotic Ca-alginate beads spiked by lactose; second part was mixed with Ca-alginate beads spiked by commercial inulin; third part was mixed with probiotic microcapsules (external gelation) spiked by lactose; fourth part was mixed with probiotic microcapsules (external gelation) spiked by commercial inulin; fifth part was mixed with probiotic microcapsules (internal gelation) spiked by lactose; sixth part was mixed with probiotic microcapsules (internal gelation) spiked by commercial inulin; seventh part was mixed with probiotic microcapsules spiked by millet inulin, most effective for the growth of the probiotic microorganism and the eighth part was kept unfortified.

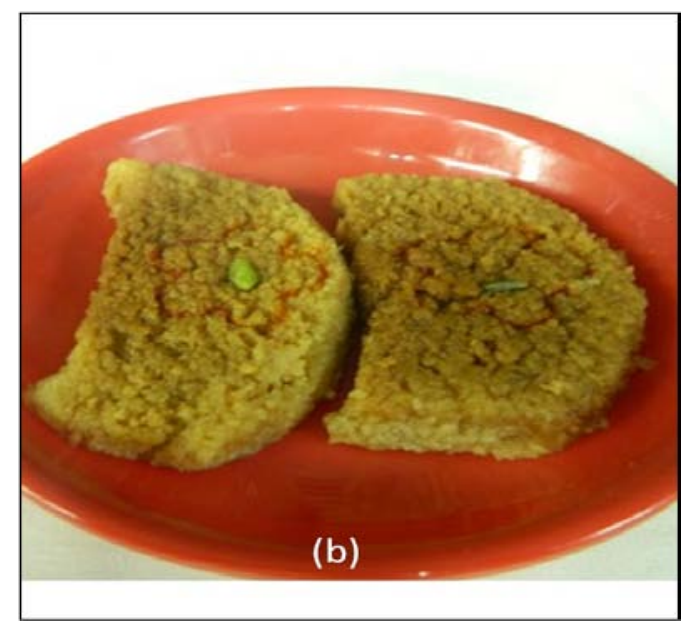

Fig. 1: Indian sweet (milk cakes) samples (a) wrapped by aluminium foil (b) original sample
From each part, one milk cake weighing $25 \mathrm{~g}$ was prepared using sterile molds. All operations for the preparation of milk cake were conducted in a UV-sterilized hood. During the fortification, $10 \%$ $(\mathrm{w} / \mathrm{w})$ beads or microcapsules were used. The milk cakes are shown in fig. 1. All milk cakes were wrapped with sterile aluminium foils (fig. 1) before preservation.

\section{Viability assay of the probiotic cells in food products}

The fortified Indian milk cakes were stored at $4{ }^{\circ} \mathrm{C}$ and $-20^{\circ} \mathrm{C}$ over a period of $4 \mathrm{w}$. Unfortified samples were used as controls. Viability assay was performed every one-week interval as per the following protocol: in a UV-sterilized hood, $5 \mathrm{ml}$ of phosphate buffer was first mixed with $1 \mathrm{~g}$ of food samples, and then $1 \mathrm{ml}$ from this mixture was serially diluted with peptone water by 10 fold for six times. $0.1 \mathrm{ml}$ of the diluted mixture was plated on MRS agar using spread plate technique. The agar plates were incubated under anaerobic condition for $24 \mathrm{~h}$ at $37^{\circ} \mathrm{C}$ and the colonies on each plate were counted. According to this technique the concentration of cells per millilitre of the original phosphate buffer solution of the food sample, $10^{7}$ times the count obtained from the spread plate method. Since $1 \mathrm{~g}$ of food sample was originally present in $5 \mathrm{ml}$ phosphate buffer, the concentration of cells in the food sample is $5^{*} 10^{7}$ times that obtained from spread plate method.

All experiments were carried out thrice, and the averages of three replicate experimental results have been reported.

\section{RESULTS AND DISCUSSION}

\section{Characteristics of millet extracts}

The presence of functional groups of inulin in the three millet samples was clearly indicated through the FTIR results (not shown). The $\%(w / w)$ of inulin in great, pearl and finger are provided in table 1 . From the analysis of the table 1 , it is clear that the inulin content of pearl millet extract is the highest among all millet extracts. The results could not be compared with the literature data due to unavailability.

Table 1: Content of inulin in millet extracts*

\begin{tabular}{ll}
\hline Millet type & Inulin in extract $\%(w / w)$ \\
\hline Great & $30.147 \pm 0.127000$ \\
Pearl & $47.27 \pm 0.155885$ \\
Finger & $32.0833 \pm 0.076376$ \\
\hline
\end{tabular}

*Values are mean $(n=3) \pm$ standard deviation (Standard deviation for sample population of three replicate observations corresponding to each mean result was calculated)

\section{Effect of naturally extracted inulin on the growth of Lactobacillus casei}

The concentrations of $L$. casei obtained using the three different millet inulins, following the procedure described in the experimental section, were compared in fig. 2 . From the analysis of the fig., it is clear that the pearl millet inulin is the most effective among all millet inulins with respect to the growth of $L$. casei. The effectiveness of pearl millet inulin was followed by that of great millet inulin and finger millet inulin. Better assimilation of the pearl millet inulin by $L$. casei in comparison to inulins derived from other millet sources was the underlying fact. This might be due to the difference in the degree of polymerization of inulin derived from different millet sources. This could be elucidated by the determination of the degree of polymerization defined by a number of monomer units (fructose) per molecule of prebiotic polymer, i.e., inulin derived from great, pearl and finger millets.

\section{Characterization of entrapped beads and microcapsules}

Table 2 shows the results of microscopic size analysis of beads and microcapsules obtained by entrapment and external/internal microemulsification techniques. It is clear that the size of beads is much larger than those of microcapsules. On the other hand, the 
microcapsules obtained through internal gelation method are much smaller than those obtained through external gelation. The results are in agreement with those reported by previous researchers $[17,20,21]$.

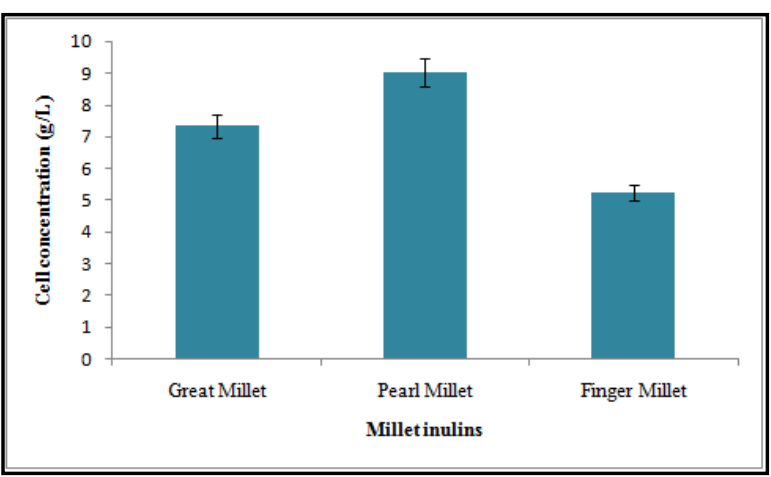

Fig. 2: Bacterial growth for three different millet inulins
Table 2: Microscopic size analysis of beads and microcapsules*

\begin{tabular}{ll}
\hline Microencapsulation processes & Bead/microcapsule diameter \\
\hline Entrapment method & $2.98333 \mathrm{~mm}( \pm 0.028868 \mathrm{~mm})$ \\
Emulsification/external gelation & $298.333 \mu \mathrm{m}( \pm 2.886751 \mu \mathrm{m})$ \\
Emulsification/internal gelation & $23.9333 \mu \mathrm{m}( \pm 0.11547 \mu \mathrm{m})$ \\
\hline
\end{tabular}

* Values are mean $(\mathrm{n}=3) \pm$ standard deviation

Viability of the probiotic cells in fortified food products after preservation

In fig. $4 \mathrm{a}$ and $4 \mathrm{~b}$ the photographs of the spread plates obtained for unfortified food samples and that fortified with encapsulated L. casei are provided. It was clearly indicated that while the control was fully contaminated, no contamination was present in the case of the fortified one. This establishes the anti-microbial activity of the immobilized probiotic culture against contaminating microorganisms and the elongation of shelf life. Due to unavailability of literature data, the results could not be compared.

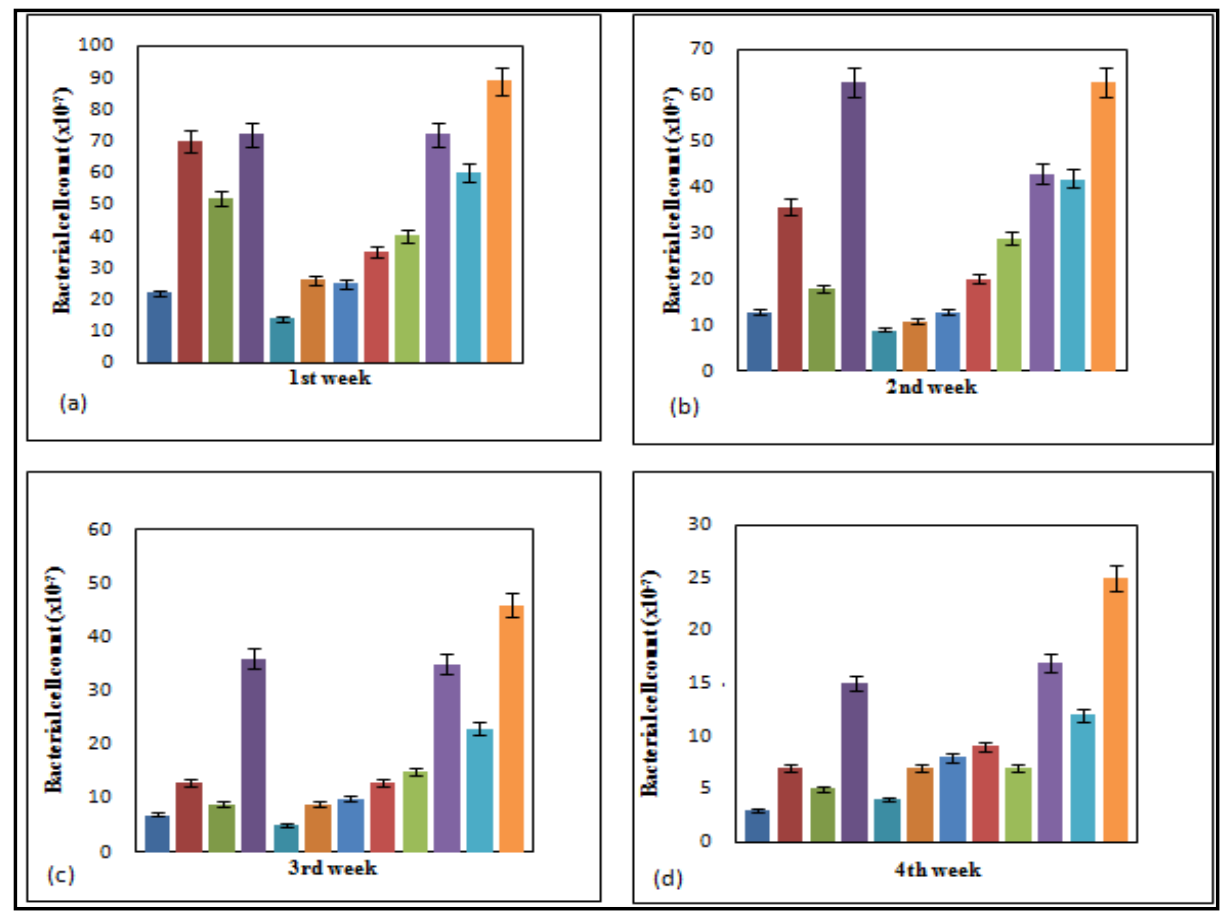

Fig. 3: Comparison of effects of immobilization methods and fortification vectors (only probiotic or Probiotic-commercial inulin) on viability of probiotics in fortified milk cakes preserved at $4^{\circ} \mathrm{C}$ and-20 ${ }^{\circ} \mathrm{C}, \square$ : External gelation (Probiotic) $\left(4^{\circ} \mathrm{C}\right)$; $\square$ : External gelation (Probiotic) $\left(-20^{\circ} \mathrm{C}\right)$; : External gelation (Probiotic-commercial inulin) $\left(4^{\circ} \mathrm{C}\right)$; : : External gelation (Probiotic-commercial inulin)($\left.20^{\circ} \mathrm{C}\right)$; : Ca-entrapped (Probiotic) $\left(4^{\circ} \mathrm{C}\right)$; : Ca-entrapped (Probiotic) $\left(-20^{\circ} \mathrm{C}\right) ; \quad$ : Ca-entrapped (Probiotic-commercial inulin) $\left(4^{\circ} \mathrm{C}\right)$; : Ca-entrapped (Probiotic-commercial inulin) $\left(-20^{\circ} \mathrm{C}\right) ; \quad:$ Internal gelation (Probiotic) $\left(4^{\circ} \mathrm{C}\right)$; : Internal gelation $(\mathrm{Probiotic})\left(-20^{\circ} \mathrm{C}\right) ;$ : Internal gelation (Probiotic-commercial inulin) $\left(4^{\circ} \mathrm{C}\right) ; \quad$ : Internal gelation (Probiotic-commercial inulin) $\left(-20^{\circ} \mathrm{C}\right)$.

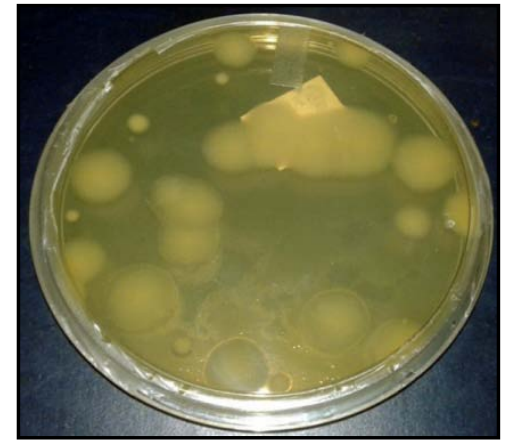

Fig. 4a: Plate for control sample of milkcake (without probiotics) on $4^{\text {th }}$ week after preservation at $4^{\circ} \mathrm{C}$

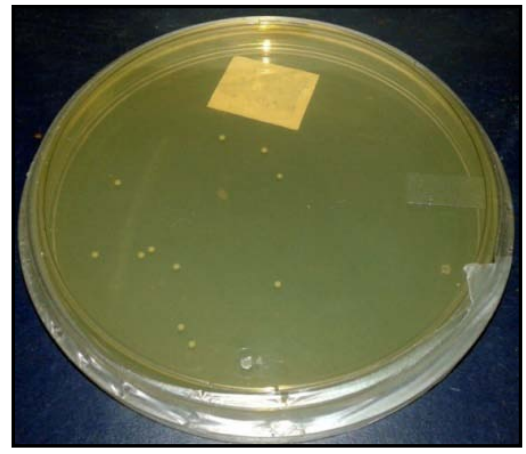

Fig. 4b: Plate for milk cake sample fortified with encapsulated probiotics on $4^{\text {th }}$ week after preservation at $4^{\circ} \mathrm{C}$ 
In table 3, the concentrations of probiotic cells in the fortified Indian milk cakes have been provided.

Table 3: Results of viability assay (cell concentrations) for fortified milk cakes*

\begin{tabular}{|c|c|c|c|c|c|c|c|c|c|c|c|c|c|c|}
\hline \multirow[t]{3}{*}{ Weeks } & \multicolumn{4}{|c|}{$\begin{array}{l}\text { Microcapsules (External gelation) } \\
\left({\left.\mathrm{x} 10^{-7}\right) / \mathrm{ml}}\right.\end{array}$} & \multicolumn{4}{|c|}{$\begin{array}{l}\text { Beads (Entrapment) } \\
\left({\left.\mathrm{x} 10^{-7}\right) / \mathrm{ml}}\right.\end{array}$} & \multicolumn{6}{|c|}{ 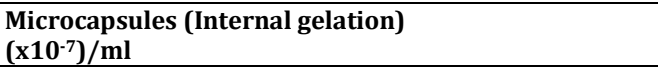 } \\
\hline & \multicolumn{2}{|c|}{ PRO } & \multicolumn{2}{|c|}{ PRO+CI } & \multicolumn{2}{|c|}{ PRO } & \multicolumn{2}{|c|}{ PRO+CI } & \multicolumn{2}{|c|}{ PRO } & \multicolumn{2}{|c|}{ PRO+CI } & \multicolumn{2}{|c|}{ PRO+PMI } \\
\hline & A & B & A & B & A & B & A & B & A & B & A & B & A & B \\
\hline \multirow[t]{2}{*}{1} & $22.0 \pm$ & $69.6 \pm$ & $51.6 \pm$ & $72 \pm$ & $13.6 \pm$ & $25.6 \pm$ & $24.6 \pm$ & $34.6 \pm$ & $40 \pm$ & $71.6 \pm$ & $60 \pm$ & $88.6 \pm$ & $84.6 \pm$ & $94.6 \pm$ \\
\hline & 0.000 & 0.577 & 0.577 & 0.000 & 0.577 & 0.577 & 0.577 & 0.577 & 0.000 & 0.577 & 0.000 & 0.577 & 0.577 & 0.577 \\
\hline \multirow[t]{2}{*}{2} & $12.7 \pm$ & $35.6 \pm$ & $17.6 \pm$ & $62.6 \pm$ & $9 \pm$ & $10.6 \pm$ & $13 \pm$ & $19.6 \pm$ & $28.6 \pm$ & $43 \pm$ & $41.6 \pm$ & $62.6 \pm$ & $42.6 \pm$ & $64 \pm$ \\
\hline & 0.577 & 0.577 & 0.577 & 0.577 & 0.000 & 0.577 & 0.000 & 0.577 & 0.577 & 0.000 & 0.577 & 0.577 & 0.577 & 0.000 \\
\hline \multirow[t]{2}{*}{3} & $6.7 \pm$ & $13 \pm$ & $8.6 \pm$ & $35.6 \pm$ & $4.6 \pm$ & $9 \pm$ & $9.6 \pm$ & $12.6 \pm$ & $14.6 \pm$ & $34.6 \pm$ & $21.6 \pm$ & $46 \pm$ & $23.6 \pm$ & $37.6 \pm$ \\
\hline & 0.577 & 0.000 & 0.577 & 0.577 & 0.577 & 0.000 & 0.577 & 0.577 & 0.577 & 0.577 & 0.577 & 0.000 & 0.577 & 0.577 \\
\hline \multirow[t]{2}{*}{4} & $3.3 \pm$ & $7 \pm$ & $5 \pm$ & $14.6 \pm$ & $3.6 \pm$ & $6.6 \pm$ & $7.6 \pm$ & $9 \pm$ & $6.6 \pm$ & $16.6 \pm$ & $11.6 \pm$ & $24.6 \pm$ & $11 \pm$ & $24.6 \pm$ \\
\hline & 0.577 & 0.000 & 0.000 & 0.577 & 0.577 & 0.577 & 0.577 & 0.000 & 0.577 & 0.577 & 0.577 & 0.577 & 0.000 & 0.577 \\
\hline
\end{tabular}

For table 3, PRO: fortified with only probiotic; PRO+CI: fortified with probiotics and commercial inulin; PRO+PMI: fortified with probiotics and pearl millet inulin; A: preservation at $4{ }^{\circ} \mathrm{C}$; B: $-20^{\circ} \mathrm{C}$, ${ }^{*}$ Values are mean $(\mathrm{n}=3) \pm$ standard deviation

The concentrations of viable $L$. casei cells in milk cake samples fortified by either beads or microcapsules containing either only probiotics or mixture of probiotics and prebiotic commercial inulin derived from chicory and preserved for 1, 2, 3 and $4 \mathrm{w}$ respectively were depicted in the bar plots in fig. $3 a, 3 b, 3 c$ and $3 d$.

It was clearly indicated in the fig. 3a-3d that irrespective of the methods of immobilization, fortification vectors and period of preservation, the viability of the cells was more for preservation condition of $-20^{\circ} \mathrm{C}$ in comparison to that exhibited at $4{ }^{\circ} \mathrm{C}$. This is due to better preservation of cells at $-20{ }^{\circ} \mathrm{C}$ compared to that at $4{ }^{\circ} \mathrm{C}$. Similar observations were obtained by Martin et al. during their studies on the preservation of immobilized L. fermentum at- $20{ }^{\circ} \mathrm{C}$ and $4{ }^{\circ} \mathrm{C}$ for $30 \mathrm{~d}$. [22] Irrespective of immobilization method preservation temperature and fortification vector, it was observed that the viability of cells decreased even at- $20^{\circ} \mathrm{C}$ with the increase of preservation period. This might be due to the formation of ice crystals on prolonged preservation causing the destruction of probiotic cells. When the effect of immobilization method on the viability of cells was analysed, it was revealed that whatever might be the fortification vector and the preservation time and condition, the best viability of cells was shown by the microcapsules produced through internal gelation method. This was justified by the fact that due to the small size of microcapsules the surface area available for the transport of substrates present in the extracellular food materials into the cells was increased resulting in more sustainability of cells. This was also due to the low leakage of cells from the microcapsules in the case of internal gelation beads as compared to the external beads, and the Ca-alginate entrapped beads $[17,22]$. The better viability of preserved probiotic cells immobilized through internal gelation in comparison to those immobilized with entrapment and external gelation techniques had also been observed by other researchers [17]. It was clearly indicated from the comparison of the performance of fortification vectors that irrespective of immobilization method and preservation period, the best viability of cells was exhibited by the coimmobilized combination of probiotic cells and commercial inulin. This was due to the fact that even under the immobilized condition, the prebiotic inulin served as a suitable substrate for the sustainability of the probiotic cells. As no reported data was so far available on the effect of co-immobilization of $L$. casei and a prebiotic compound, the comparison could be made with the literature data. It was observed that the variation of the probiotic cell count (CFU) in the $0.2 \mathrm{~g} / \mathrm{ml}$ solution of food sample in phosphate buffer, as described under experimental section, was in the range of 3-95 $\mathrm{x} 10^{7} / \mathrm{ml}$ and was much higher than the recommended lower limit of cell count of $10^{6} \mathrm{CFU} / \mathrm{ml}$ in probiotic food. Thus all the milk cakes fortified by different vectors were suitable as probiotic food. Among all samples, a combination of probiotic cells with prebiotic inulin, immobilized through internal gelation, were the most effective one. As per expectation, the prebiotic inulin was effective in enhancement and sustainability of probiotic cells even in coimmobilized condition. All the food samples were suitable for human intake even after $4 \mathrm{w}$ of preservation. The viability of probiotic cells in milk cakes fortified by microcapsules produced through internal gelation containing combinations of $L$. casei and either commercial inulin or pearl millet inulin was indicated by the fig. 5 .

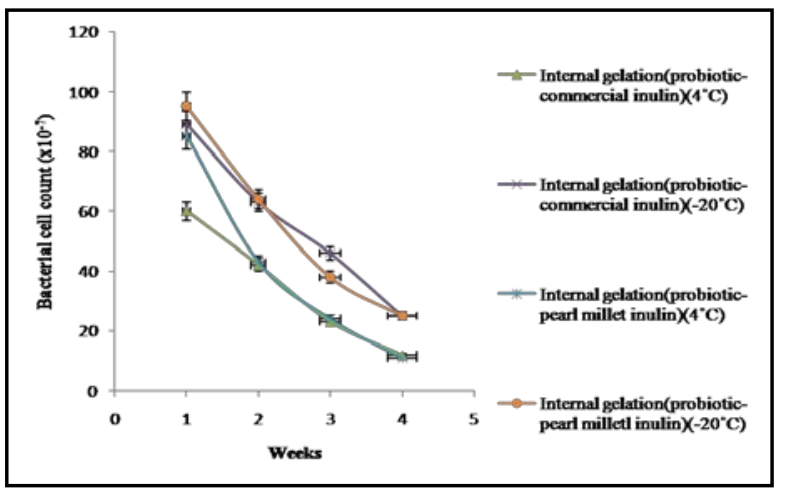

Fig. 5: Comparison of effect of microcapsules obtained by internal gelation method for both the combination probiotic-commercial inulin and probiotic-pearl millet inulin at $4^{\circ} \mathrm{C}$ and $-20^{\circ} \mathrm{C}$ (Results are average of those obtained from three replicate observations. Standard deviation varies from 0 to 0.57735 )

It was clearly revealed from the close analysis of the fig. that the effectiveness of pearl millet inulin in the enhancement of sustainability of probiotic cells was marginally better than that of commercial inulin. This might be due to the difference in the degree of polymerization of inulin derived from chicory and pearl millet inulin. However, more experiments have to be conducted to reveal the exact fact. Therefore, the substitution of commercial inulin by this nonconventional variety of inulin should be attempted in commercial scale.

\section{CONCLUSION}

Under this study effects of different immobilization methods-Caalginate entrapment; external and internal microencapsulation, the fortification vectors, namely the probiotic cells, combination of probiotic cells and commercial inulin/pearl millet inulin, preservation temperature, $4{ }^{\circ} \mathrm{C}$ and $-20{ }^{\circ} \mathrm{C}$ and period of $1-4 \mathrm{w}$ on the sustainability of the probiotic microorganism, L. casei in fortified Indian milk cake has been investigated systematically. The pearl millet inulin has been selected based on its best performance among three millet inulins (great, pearl and finger millet) with reference to the growth of the probiotic cells, namely, L. casei in free (not immobilized) culture. To the best of our knowledge, this is the first investigation of this type. This study indicates that microencapsulation techniques including internal gelation, external gelation and direct calcium-alginate entrapment methods can significantly support the survival of the probiotic microorganisms in the fortified food product, namely Indian milk cake over a preservation period of up to $4 \mathrm{w}$ at both $4{ }^{\circ} \mathrm{C}$ and-20 
${ }^{\circ} \mathrm{C}$. However, on the basis of the viability of probiotic cells, the internal gelation technique is found to be superior to the other two immobilization techniques. The results show that the contribution of different immobilization methods in increasing the viability of probiotic bacteria in preserved and fortified milk cake follows the order: internal gelation>external gelation>Ca-entrapped. Coimmobilized probiotics with prebiotics, namely, commercial inulin/pearl millet inulin markedly increase the viability of probiotic cells over that obtained through fortification by immobilized probiotics. Thus, the use of both commercial food grade inulin and naturally derived pearl millet inulin has positive effects on the survival of the microencapsulated probiotic cells in the food products during storage. Results of the study suggest that pearl millet inulin offer marginally more potential as prebiotic than the commercial food grade inulin. Overall, the fortification results in elongation of the shelf life of the preserved due to the sustenance of growth of probiotic microorganisms which ultimately inhibit the growth of pathogenic microorganisms in the food products into which they are added. It is expected that the outcome of the present research study can be utilized for the application of pearl millet and the conventional chicory inulin (commercial) for the production of fortified food products using synergistic probiotic-prebiotic combinations co-immobilized through internal gelation technique.

\section{ACKNOWLEDGEMENT}

The first author (Debolina Banerjee) acknowledges the financial support offered by Council of Scientific and Industrial Research (CSIR), India by providing Senior Research Fellowship (File number: 9/96(0725)2K12-EMRI).

\section{CONFLICT OF INTERESTS}

\section{Declared none}

\section{REFERENCES}

1. Iyer C, Kailaspathy K. Effect of co-encapsulation of probiotics with prebiotics on increasing the viability of encapsulated bacteria under in vitro acidic and bile salt conditions and in yogurt. J Food Sci 2005;70:M18-23.

2. Parwal M, Pareek R. Probiotic:-a treatment new approach. Asian J Biochem Pharm Res 2011;3:448-54.

3. Kawatra P, Aiyappa C. Probiotics: the undervalued conquerors. Asian J Biochem Pharm Res 2015;8:97-100.

4. Solanki HK, Pawar DD, Shah DA, Prajapati VD, Jani GK, Mulla $\mathrm{AM}$, et al. Development of microencapsulation delivery system for long-term preservation of probiotics as biotherapeutics agent. BioMed Res Int 2013;620-719. http://dx.doi.org/ $10.1155 / 2013 / 620719$

5. Sekhon BS, Jairath S. Prebiotics, probiotics and synbiotics: an overview. J Pharm Educ Res 2010;1:2.

6. Ziemer CJ, Gibson GR. An overview of probiotics, prebiotics and synbiotics in the functional food concept: perspectives and future strategies. Int Dairy J 1998;8:473-9.

7. Gibson GR. Fibre and effects on probiotics (the prebiotic concept). Clin Nutr Suppl 2004;1:25-31.

8. Guarner F, Khan AG, Garisch J, Eliakim R, Gangl A, Thomson A, et al. World gastroenterology organisation practice guidelines: probiotics and prebiotics. Arab J Gastroent 2009;10:33-42.
9. Tripathi MK, Giri SK. Probiotic functional foods: survival of probiotics during processing and storage. J Func Foods 2014;9:225-41.

10. Prisco AD, Mauriello G. Probiotic action of foods: a focus on microencapsulation tool. Trends Food Sci Technol 2016;48:27-39.

11. Kailasapathy K. Microencapsulation of probiotic bacteria: technology and potential applications. Curr Issues Intest Microbiol 2002;3:39-48.

12. Krasaekoopt W, Bhandari B, Deeth $H$. Evaluation of encapsulation techniques of probiotics for yogurt. Int Dairy J 2003;13:3-13.

13. Anal AK, Singh H. Recent advances in microencapsulation of probiotics for industrial applications and targeted delivery. Trends Food Sci Technol 2007;18:240-51.

14. Chavarri M, Maranon I, Villaran MC. Encapsulation technology to protect probiotic bacteria. Bioprocess and Preserv Area 2012;501-29. Doi:10.5772/50046.

15. Banerjee D, Chowdhury R, Bhattacharya P. The prebiotic influence of inulin on growth rate and antibiotic sensitivity of Lactobacillus casei. Int J Pharm Pharm Sci 2016;8:181-4.

16. Samanta (Koruri) S, Banerjee D, Chowdhury R, Bhattacharya P. Studies on prebiotic food additive (inulin) in Indian dietary fibre sources garlic (Allium sativum), wheat(Triticum spp.),oat(Avena sativa) and dalia(Bulgur). Int J Pharm Pharm Sci 2014;6:278-82.

17. Chan ES, Wong SL, Lee PP, Lee JS, Ti TB, Zhang Z, et al. Effects of starch filler on the physical properties of lyophilized calciumalginate beads and the viability of encapsulated cells. Carbohydr Polym 2011;83:225-32.

18. Yoo IK, Seong GH, Chang HN, Park JK. Encapsulation of Lactobacillus casei cells in liquid-core alginate capsules for lactic acid production. Enzyme Microbiol Technol 1996; 19:426-33.

19. Song H, Yua W, Gaoa M, Liub X, Maa X. Microencapsulated probiotics using emulsification technique coupled with internal or external gelation process. Carbohydr Polym 2013;96:181-9.

20. Ribeiro AJ, Silva C, Ferreira D, Veiga F. Chitosan-reinforced alginate microspheres obtained through the emulsification/ internal gelation technique. Eur J Pharm Sci 2005;25:31-40.

21. Sultana K, Godward G, Reynolds N, Arumugaswamy R, Peiris P, Kailasapathy K. Encapsulation of probiotic bacteria with alginate-starch and evaluation of survival in simulated gastrointestinal conditions and in yoghurt. Int J Food Microbiol 2000;62:47-55.

22. Martin MJ, Villoslada FL, Ruiz MA, Morales ME. Effect of unmodified starch on the viability of alginate-encapsulated Lactobacillus fermentum CECT5716. LWT-Food Sci Technol 2013;53:480-6.

\section{How to cite this article}

- Debolina Banerjee, Puja Bag, Ranjana Chowdhury, Pinaki Bhattacharya. Sustainability of the probiotic Lactobacillus casei in fortified Indian milk cakes under different preservation conditions-effects of co-immobilization of $l$. Casei and commercial prebiotic inulin (chicory based) and millet inulin. Int J Pharm Pharm Sci 2017;9(1):152-157. 